\title{
Influence of the Sodium Content on the Reactivity of Carbon Anodes
}

\author{
Jefferson dos Santos Batista ${ }^{\mathrm{a}}$, Benedito Inácio da Silveira ${ }^{\text {b* }}$ \\ ${ }^{a}$ Red Area Management, Alumínio do Norte do Brasil S.A. - ALUNORTE, \\ Barcarena - PA, Brazil \\ ${ }^{\mathrm{b}}$ Faculty of Chemical Engineering, Federal University of Pará - UFPA, \\ R. Augusto Correa, 01, Guamá, 66075-110 Belém - PA, Brazil
}

Received: March 7, 2008; Revised: September 19, 2008

\begin{abstract}
Spent anodes, denominated butts in the aluminum industry, are recycled as part of the raw material used to produce new anodes. The fragmentation of the butt generates some sodium-rich powder, which is captured and included in the recycled material. This paper evaluates the influence of sodium content on anode reactivity. Six formulations with 0 to $25 \%$ butt powder were used. An average increase of $48 \mathrm{ppm}$ of sodium from one to another formulation caused average increments of 3.38 and $2.72 \%$ for air and $\mathrm{CO}_{2}$ reactivity, respectively. The quality-related figures varied from 1.34 to 1.12 for $\mathrm{CO}_{2}$ and from 1.10 to 0.62 for air, showing quality loss in higher sodium content and higher impact on air reactivity. The Fischer formula predicted a carbon specific consumption of $-48.47 \mathrm{~kg} . \mathrm{t}^{-1} \mathrm{Al}$ for baked carbon anodes with $127 \mathrm{ppm}$ to $367 \mathrm{ppm}$ of sodium content, showing that the sodium can cause relevant carbon losses and increase costs of the aluminum production.
\end{abstract}

Keywords: butt, aluminum, spent anode, anode reactivity

\section{Introduction}

The Hall-Héroult process is the only method currently used to produce aluminum in the primary aluminum industry. In this process, aluminum is produced in electrolytic pots into which alumina $\left(\mathrm{Al}_{2} \mathrm{O}_{3}\right)$ is fed and dissolved in molten cryolite $\left(\mathrm{Na}_{3} \mathrm{AlF}_{6}\right)$ at about $960{ }^{\circ} \mathrm{C}$. Molten aluminum is formed on the base of the carbon cathode in the pot, while oxygen ions released from the dissociation of the alumina react with the carbon anode blocks, generating carbon dioxide $\left(\mathrm{CO}_{2}\right)$. Good quality carbon anodes should be oxidation-resistant in gaseous environments in order to minimize losses due to air oxidation on the surface of the exposed piece $\left(\mathrm{C}+\mathrm{O}_{2} \rightarrow \mathrm{CO}_{2}\right)$ and carbon oxidation caused by the carbon dioxide generated during the aluminum production $\left(\mathrm{CO}_{2}+\mathrm{C} \leftrightarrow 2 \mathrm{CO}\right)^{1}$. Some methods, such as the bench scale method, are broadly used to measure anode reactivity with a quality control purpose. Finding out that the anodes have low quality when in use usually generates undesirable costs. For this reason, the production of test specimen in bench scale is one of the methods used to assess the quality of the anodes within the composition of interest and subsequent evaluation of some of their properties ${ }^{1}$. As the anode life in the electrolytic cells comes to an end, the residual anodes, called butts, remain attached to the rod. These are recycled as a component of the anode production process. In this recycling process, the butts are crushed, generating a type of powder, which is captured and, despite containing some impurities, is also recycled into the process. These impurities have strong influence on the consumption of the anode in the electrolytic cells, and the main necessity to control them arises from the fact that they may have significant oxidation catalyzing effects in the operation of electrolytic cells. Amongst the main impurities acting as catalysts of the oxidation reactions is the chemical element sodium ( $\mathrm{Na}$ ). Although it is well documented that sodium acts as a catalyst of carbon oxidation reactions, no significant relationship with the oxidation of anodes was obtained ${ }^{1}$.

This paper aims at assessing the influence of sodium content in the powder generated by butt crushing on the carbon anode reactivity and the impact of the impurities on the quality figures to both air and $\mathrm{CO}_{2}$, in addition to the predicted specific carbon consumption using the Fischer formula ${ }^{2}$.

\section{Materials and Methods}

Coke, pitch and butt powder were collected according to the mass balance for each required bench scale anode formulation. The components were mixed, homogenized and characterized through chemical analyses by $\mathrm{X}$ ray fluorescence and atomic absorption. The fractions of the formulations were obtained by grain size classification ${ }^{3}$. Based on a sodium mass balance and considering the butt powder size distribution, six formulations were prepared with amounts of butt powder ranging from 0 to $25 \%$ of the fines fraction. The total sodium concentration $\left(\mathrm{Na}_{\text {total }}\right)(\mathrm{ppm})$ was calculated through equation:

$$
\begin{aligned}
& N a_{\text {total }}=N a_{P} P+(1-P) \\
& \left(N a_{C} C+N a_{M} M+N a_{F} F+N a_{B} B\right)
\end{aligned}
$$

where $\mathrm{P}, \mathrm{C}, \mathrm{M}, \mathrm{F}$ and $\mathrm{B}$ are the percentages of pitch, coarse, medium and fine fractions and butt powder, respectively, used in the formulations. $\mathrm{Na}_{\mathrm{P}}, \mathrm{Na}_{\mathrm{C}}, \mathrm{Na}_{\mathrm{M}}, \mathrm{Na}_{\mathrm{F}}$ and $\mathrm{Na}_{\mathrm{B}}$ are the sodium concentrations (ppm) in P, C, M, F and B, respectively. The preparation and development of the anodes from the formulations were carried out in an equipment called bench scale R \& D Carbon 189-161 and based on the internal procedure of the Alumínio Brasileiro Company S.A. $(\text { ALBRAS })^{3}$. For each formulation, $50 \mathrm{~mm}$ diameter and $130 \mathrm{~mm}$ height test specimens were prepared. The following analyses were carried out: $\mathrm{X}$ ray fluorescence, thermal conductivity ${ }^{4}$, air permeability $^{5}$, air reactivity ${ }^{6}$, and $\mathrm{CO}_{2}$ reactivity ${ }^{7}$.

The anode quality figures are functions of the residue of $\mathrm{CO}_{2}$ reactivity (RRCO), RRCO standard deviation $\left(\sigma_{\mathrm{RRCO}}\right)$, and air per-

*e-mail: inacio@ufpa.br 
meability $(\mathrm{PM})^{8}$. In order to calculate the quality figure to the $\mathrm{CO}_{2}$ $\left(\mathrm{Q}_{\mathrm{CO}_{2}}\right)$, the following equation was used:

$$
Q_{\mathrm{CO}_{2}}=\frac{3.7 x\left(\mathrm{RRCO}-2 x \sigma_{R R C O}\right)-9.3 x P M}{260}
$$

where RRCO, $\sigma_{\mathrm{RRCO}}$, and PM are expressed in $\%, \%$ and $\mathrm{nPm}$, respectively.

The anode resistance to air oxidation is a function of the reactivity residue to the air (RRAir), RRAir standard deviation $\left(\sigma_{\text {RRAir }}\right)$, thermal conductivity (TC), and air permeability $(\mathrm{PM})^{8}$. In order to calculate the quality figure to the air $\left(\mathrm{Q}_{\text {air }}\right)$, the following equation was used:

$$
Q_{\text {Air }}=\left[1.5 \times\left(R R A \text { ir }-2 \times \sigma_{\text {RRAir }}\right)-8.0 \times T C-5.0 \times P M\right] / 646
$$

where RRAir, $\sigma_{\text {RRAir }}$ TC and PM are expressed in $\%$, w. $\mathrm{mK}^{-1}$, and $\mathrm{nPm}$, respectively.

The quality figures to the $\mathrm{CO}_{2}$ and air of the anodes were assessed and eventually used to evaluate the behavior of the anodes obtained in laboratory as a function of the sodium concentration. In order to foresee the impact of the sodium concentration on the specific carbon consumption concerning the main properties of the anode quality control, the Fischer formula was used. In this paper, in order for the Fischer formula to be applied, the reactivity residues to the air and $\mathrm{CO}_{2}^{2-9}$ in the following equation were used:

$$
\Delta N C=-1.7 x \Delta R R C O-1.5 x \Delta R R A i r
$$

where $\triangle N C, \triangle R R C O$ and $\triangle R R A i r$ are the variations of specific carbon consumption, reactivity residue to the $\mathrm{CO}_{2}$, and reactivity residue to the air, respectively.

\section{Results and Discussion}

The data of sodium concentration and the results obtained from the sodium mass balance with respect to the butt powder are presented in Table 1.

Table 1 data show that the lowest total sodium concentration, $118.45 \mathrm{ppm}$, is found in the formulation where butt powder is not added, and the highest one, $296.1 \mathrm{ppm}$, is in the formulation with $25 \%$ butt powder.

Table 2 shows the results of the analyses carried out with samples of baked anode prepared in bench scale with the six formulations.

From the results in Table 2, one can observe that the increase of sodium concentration in the carbon anodes causes an increase in $\mathrm{CO}_{2}$ and air reactivity. These results also show that only for the case where butt powder was not added, the values of RRAir can be considered as typical; values between 65 and 90\%, for all the other results obtained in different sodium concentrations, the values of RRAir are out of the standards generally found for this pattern ${ }^{10}$. The TC values showed in Table 2 are lower than the typical range found for this property, such as values between 3.0 and $4.5 \mathrm{~W}(\mathrm{~m} . \mathrm{K})$.
Figure 1 shows the changes in the residue from $\mathrm{CO}_{2}$ reactivity (RRCO) as a function of the increase in sodium concentration in the anodes.

The results shown in Figure 1 demonstrate that the values of RRCO decreased with the increase of the sodium concentration, indicating that there was an increase in $\mathrm{CO}_{2}$ reactivity with the increase in sodium concentration. In other words, there was an acceleration of the reaction $\mathrm{CO}_{2}+\mathrm{C} \leftrightarrow 2 \mathrm{CO}$ with the increase in the fraction of butt powder in the samples ${ }^{11}$. From the results, one can also observe that, on average, $48 \mathrm{ppm}$ of sodium cause a decrease of $2.72 \%$ in the RRCO values. Then, sodium is acting as a catalyst of $\mathrm{CO}_{2}$ reactivity, causing a total loss of RRCO by $13.6 \%$. According to the determination coefficient $\mathrm{R}^{2}$ obtained for the adjustment of the curve of the Figure 1 there is a strong dependence on the RRCO with respect to sodium content ${ }^{12}$.

Figure 2 shows the changes of the RRAir as a function of the sodium concentration in the bench scale carbon anodes.

Figure 2 results show that the values of RRAir decreased with the increase of sodium concentration. The value of $367 \mathrm{ppm}$ of

Table 2. Results of the analyses of the samples prepared in bench scale.

\begin{tabular}{cccccc}
\hline $\begin{array}{c}\text { Butt's } \\
\text { powder }(\%)\end{array}$ & $\begin{array}{c}\mathrm{Na} \\
(\mathrm{ppm})\end{array}$ & $\begin{array}{c}\text { TC } \\
\mathrm{W}(\mathrm{m} . \mathrm{K})\end{array}$ & $\begin{array}{c}\mathrm{PM} \\
(\mathrm{nPm})\end{array}$ & $\begin{array}{c}\text { RRCO } \\
(\%)\end{array}$ & $\begin{array}{c}\text { RRAir } \\
(\%)\end{array}$ \\
\hline 0 & 127 & 2.50 & 0.78 & 97.6 & 67.3 \\
5 & 163 & 2.24 & 1.54 & 94.3 & 61.1 \\
10 & 204 & 1.92 & 1.12 & 93.4 & 58.9 \\
15 & 286 & 2.12 & 0.84 & 91.1 & 57.4 \\
20 & 339 & 2.93 & 1.27 & 88.5 & 55.2 \\
25 & 367 & 2.86 & 1.91 & 84.0 & 50.4 \\
\hline
\end{tabular}

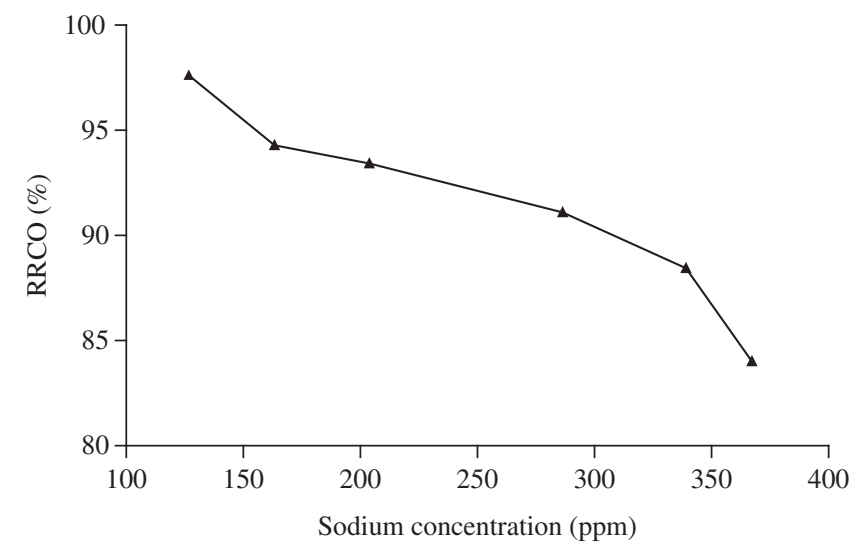

Figure 1. RRCO (\%) changes as a function of the sodium concentration

\begin{tabular}{|c|c|c|c|c|c|c|}
\hline \multirow{2}{*}{$\begin{array}{l}\text { Component } \\
\text { Pitch }\end{array}$} & \multicolumn{6}{|c|}{ Sodium concentration (ppm) } \\
\hline & 172 & 172 & 172 & 172 & 172 & 172 \\
\hline Coarse fraction & 103 & 103 & 103 & 103 & 103 & 103 \\
\hline Medium fraction & 101 & 101 & 101 & 101 & 101 & 101 \\
\hline Fine fraction & 121 & 121 & 121 & 121 & 121 & 121 \\
\hline Butt's powder & 957 & 957 & 957 & 957 & 957 & 957 \\
\hline Butt's powder $(\%)$ & 0 & 5 & 10 & 15 & 20 & 25 \\
\hline $\mathrm{Na}_{\text {total }}$ & 118.45 & 153.98 & 189.51 & 225.04 & 260.57 & 296.10 \\
\hline
\end{tabular}
(ppm).

Table 1. Total sodium content in each formulation. 


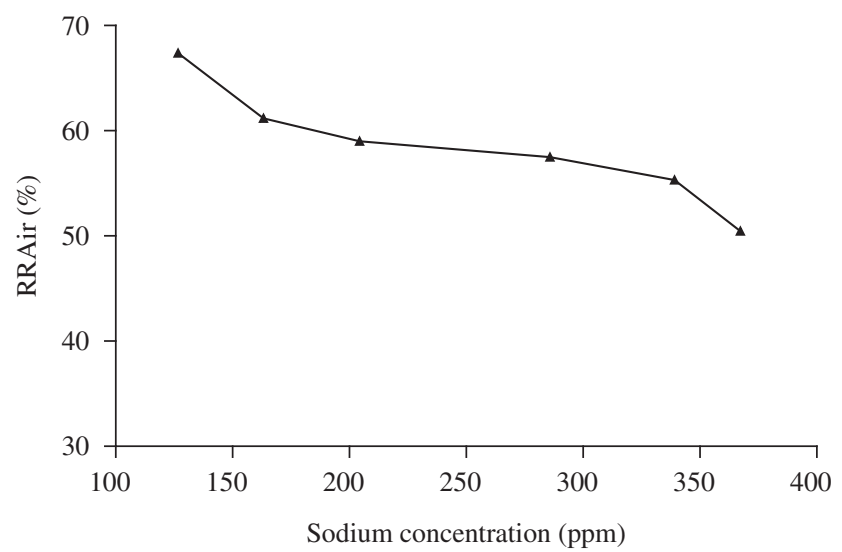

Figure 2. RRAir (\%) changes as a function of the sodium concentration (ppm).

sodium caused the lowest value for RRAir, 50.4\%, indicating a negative effect of the sodium content on the reactivity residue to the air from the anodes. This means that it has an acceleration of reaction $\mathrm{O}_{2}+\mathrm{C} \leftrightarrow \mathrm{CO}_{2}$. On average, increments of $48 \mathrm{ppm}$ of sodium content from one formulation to another caused an average loss of $3.38 \%$ of RRAir, and a total loss of the observed RRAir of $16.9 \%$. This behavior shows the catalytic effect of sodium on air reactivity, confirming what is described in the literature ${ }^{13}$.

The catalytic effect of the sodium (Na) observed both for the $\mathrm{CO}_{2}$ reactivity and for air reactivity can cause, in addition to the deterioration of the carbon anode properties, an increase in the excessive consumption of anodes, temperature of the electrolytic bath as a function of the higher powder generation, loss of current efficiency, etc. ${ }^{11}$.

In the range of the studied sodium concentration, the data of Figure 2 were adjusted to a third order polynomial equation, and the determination coefficient $\mathrm{R}^{2}$ showed a strong dependence degree of RRAir with respect to the sodium concentration.

The profile for the quality figure to the $\mathrm{CO}_{2}\left(\mathrm{Q}_{\mathrm{CO}_{2}}\right)$ is shown in Figure 3.

From the results of Figure 3 it is observed that the values of $\mathrm{Q}_{\mathrm{CO}_{2}}$ are higher than 1 , meaning that the obtained anodes are of good quality with respect to the $\mathrm{CO}_{2}^{8}$. When the sodium concentration changed from $127 \mathrm{ppm}$ to $367 \mathrm{ppm}$, the values of $\mathrm{Q}_{\mathrm{CO}_{2}}$ decreased from 1.34 to 1.12 indicating a quality decrease of the anodes with respect to the $\mathrm{CO}_{2}$ reactivity.

In Figure 4 it is shown the profile for the quality figure to the air $\left(Q_{\text {Air }}\right)$ for the carbon anodes studied.

Figure 4 results show that the only formulation with $Q_{\text {Air }}$ value higher than 1 was that prepared without the addition of butt powder. For all the others, $\mathrm{Q}_{\text {Air }}$ values are lower than 1, indicating that the sodium-rich anodes prepared with butt powder are of bad quality with respect to the air ${ }^{8}$. The strong quality drop observed in the formulations prepared with 20 to $25 \%$ butt powder, is probably explained by the combined effect of the higher air permeability in those formulations (see results in Table 2). The $\mathrm{Q}_{\text {Air }}$ values shown in Figure 4 decreased from 1.10 to 0.62 , while the values of $\mathrm{Q}_{\mathrm{CO}_{2}}$ shown in Figure 3 decreased from 1.34 to 1.12 , showing that sodium had greater influence on air reactivity than on $\mathrm{CO}_{2}$ reactivity.

By applying the Fischer formula to estimate the specific carbon consumption, the following result was obtained.

$$
\begin{aligned}
& \Delta N C=-1.7 \times(97.6-84.0)-1.5 \times(67.3-50.4)= \\
& -(1.7 \times 13.6)-(1.5 \times 16.9)=-48.47 \mathrm{~kg} / \mathrm{t} \mathrm{Al}
\end{aligned}
$$

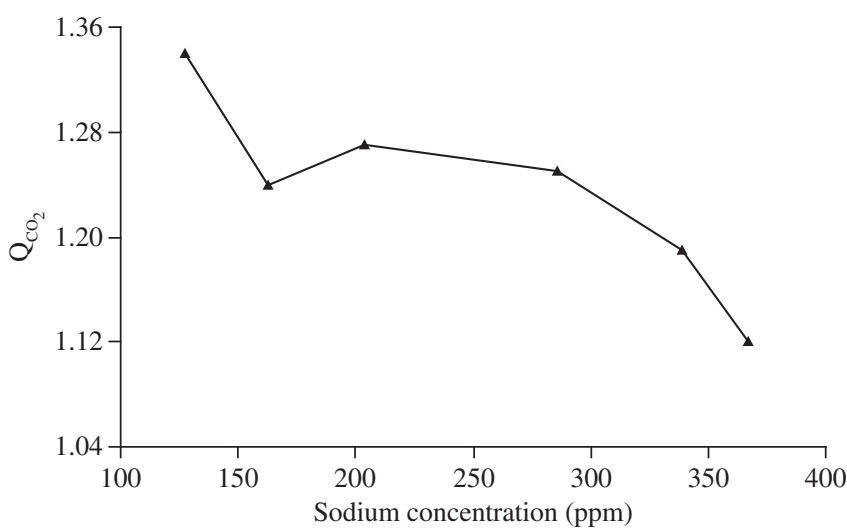

Figure 3. Quality figure to the $\mathrm{CO}_{2}\left(\mathrm{Q}_{\mathrm{CO} 2}\right)$ as a function of the sodium concentration (ppm).

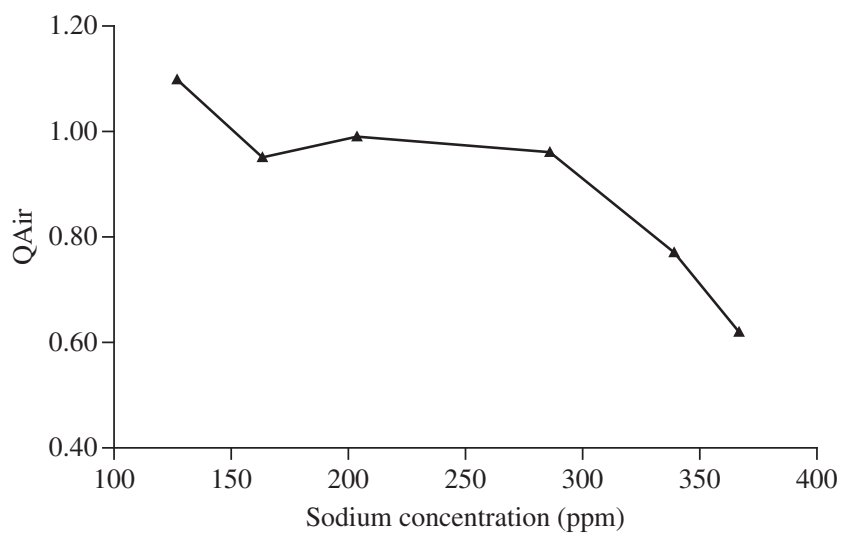

Figure 4. Quality figure to the air $\left(\mathrm{Q}_{\mathrm{Air}}\right)$ as a function of the sodium concentration $(\mathrm{ppm})$.

On the basis of such result, it was estimated that if there is a range of sodium concentration from $127 \mathrm{ppm}$ to $367 \mathrm{ppm}$ in the baked carbon anode required for aluminum production, then there will be relevant losses that require greater amounts of anode pieces for the same production, thus increasing the specific consumption and production costs for this metal ${ }^{14}$.

\section{Conclusions}

The results have shown that the higher the sodium concentration in the carbon anodes, the lower the reactivity residues to air and $\mathrm{CO}_{2}$, thus demonstrating higher catalytic activity and susceptibility to the reactivity by the anodes produced. For sodium concentration changes from 127 to $367 \mathrm{ppm}$, the reactivity residues to $\mathrm{CO}_{2}$ changed from 97.6 to $84.0 \%$ and the air changed from 67.3 to $50.4 \%$, respectively. For an average increase of $48 \mathrm{ppm}$ in the sodium concentration from one formulation to another, there was an average loss of $2.72 \%$ for the reactivity residue to $\mathrm{CO}_{2}$ and $3.38 \%$ to air, showing higher catalytic effect on the reactivity to air.

The quality figure to the $\mathrm{CO}_{2}$ values obtained for carbon anodes manufactured with different sodium concentrations indicated that all the samples analyzed are of good quality, but with strong tendency to drop as the sodium concentration increases. The quality figure of the air oxidation had only one formulation without butt powder, which showed anodes of good quality, all the others with butt powder 
in their preparation showed bad quality; $\mathrm{Q}_{\mathrm{Air}}$ values changed from 1.10 to 0.62 . The Fischer formula prediction of the specific carbon consumption, taking into account the impact from sodium concentration, resulted in the value of $\Delta \mathrm{NC}=-48.47 \mathrm{~kg} \cdot \mathrm{t}^{-1} \mathrm{Al}$, which means that there was a relevant increase in the specific carbon consumption and on aluminum production costs.

\section{Acknowledgements}

The authors are thankful to ALBRAS, Alumínio Brasileiro S. A. Co., for the financial support.

\section{References}

1. Hume SM. Anode Reactivity - Influence of Raw Material Properties. 2 ed. Sierre, Switzerland: R\&D Carbon Ltd.; 1999.

2. Mori Z. Practical. Experience with a Formula for the Prediction of the Anode Consumption, 1993. In: Anodes for the Aluminum Industry. 1 ed. Sierre, Switzerland: R\&D Carbon Ltd.; 1995. p. 369-379.

3. RDC 161. Bench Scale Plant: Instructions. Sierre, Switzerland: R\&D Carbon Ltd; 1989.

4. RDC 143. Thermal Conductivity. Sierre, Switzerland: R\&D Carbon Ltd; 1989.

5. RDC 145. Air Permeability. Sierre, Switzerland: R\&D Carbon Ltd; 1989.
6. RDC 151. Air Reactivity of Electrodes. Sierre, Switzerland: R\&D Carbon Ltd; 1989.

7. RDC 146. $\mathrm{CO}_{2}$ Reactivity of Electrodes. Sierre, Switzerland: R\&D Carbon Ltd; 1989.

8. Keller F. Anode Quality Figures. In: Anodes for the Aluminum Industry. 1 ed. Sierre, Switzerland: R\&D Carbon Ltd.; 1995. p. 355-357.

9. Moura RR. Venda de Finos: Estudo de Viabilidade Econômica. Relatório interno ALBRAS, 2001. Barcarena, PA: ALBRAS; 2001.

10. Hulse KL. Anode Manufacture - Raw Materials, Formulation and Processing Parameters. 1 ed. Sierre. Switzerland: R\&D Carbon Ltd.; 2000.

11. Meier MW. All about $\mathrm{CO}_{2}$ and Air Reactivity of Anodes. One Day Course, Albras on 2003 May 14. Barcarena: R\&D Carbon Ltd.; 2003.

12. Andriotti JLS. Fundamentos de Estatística e Geoestatística. São Leopoldo: Ed. Unisinos; 2003. 165 p.

13. Naterstad T. Fundamentals of Aluminium Production. In: The 18th International Course on Process Metallurgy of Aluminium; 1999 May 15-16. Norway: Norwegian University of Science and Technology Trondheim; 1999.

14. Meier MW. Anodes: The Impact of Raw Material Quality and Anode Manufacturing Parameters on the Behaviour in Electrolysis. In: The 19th International Course on Process Metallurgy of Aluminium; 2000 May 22-26. Trondheim, Norway: Norwegian University of Science and Technology; 2000. 